\title{
A NEW APPLE SCAB RISK MODEL THAT INTEGRATES ASCOSPORE RELEASE, INFECTION RISK AND SUSCEPTIBLE LEAF AREA
}

\author{
R.M. BERESFORD ${ }^{1}$, W.R. HENSHALL ${ }^{1}$ and J.W. PALMER ${ }^{2}$ \\ ${ }^{1}$ HortResearch, Mt. Albert Research Centre, Private Bag 92-169, Auckland \\ ${ }^{2}$ HortResearch, Nelson Research Centre, P.O. Box 220, Motueka \\ Corresponding author: rberesford@hortresearch.co.nz.
}

\begin{abstract}
A new model has been developed for assessing day-to-day variation in risk of infection of apples by Venturia inaequalis, the scab or black spot pathogen. The model comprises three components, ascospore availability, wetness-based infection risk based on "Mills periods" and susceptible leaf area. The ascospore and wetness-based infection risk components were adapted from previous models, whereas the susceptible leaf area component is new. When the model used weather data from Hawke's Bay and Nelson in spring 2003, the predicted risk incidence was determined mostly by wetness-based infection risk, but the magnitude of risk periods was greatly influenced by predicted ascospore release. The susceptible leaf area component predicted a hitherto unidentified increase in infection risk, after the peak in ascospore maturation rate had occurred. The model is intended to assist in fungicide selection and timing for scab control in New Zealand apples, but needs to be field tested before implementation.
\end{abstract}

Keywords: disease forecasting, fungicide management, ascospore release, prediction model, leaf canopy susceptibility.

\section{INTRODUCTION}

Two computer-based models are currently used in the New Zealand apple industry to assist in the selection and timing of fungicides for the management of apple scab (black spot), caused by Venturia inaequalis. The first is a weather-based infection risk model (Beresford \& Spink 1992), which identifies the periods of surface wetness that pose a high risk of infection. The second is an ascospore availability model, which identifies the periods when large numbers of ascospores are likely to be released from overwintered apple leaves on the ground (Beresford 1999). Both operate with hourly weather data and are currently available in the Metwatch ${ }^{\mathrm{TM}}$ software supplied by Hortplus Ltd.

The separate use of these two models does not show how risks associated with ascospore availability and with wetness-based infection periods interact to affect overall infection risk during the season. Ascospore and wetness-based risks are often linked through the occurrence of rainfall and the magnitude of overall risk varies greatly according to ascospore maturation patterns. Furthermore, infection risk is affected by the growth of the apple leaf canopy during the season. Apple leaves are only susceptible to infection by $V$. inaequalis while they are expanding and once fully expanded they become highly resistant to infection (Schwabe 1979, MacHardy 1996). The amount of leaf area that is expanding, and therefore the susceptibility of the whole leaf canopy to infection, varies during the season as a result of the different growth periods and growth rates of different types of apple shoots.

In this paper the concept of a new model that predicts the relative contributions of wetness-based infection, ascospore release and susceptible leaf area to overall infection risk by $V$. inaequalis is described. The model is intended for the New Zealand apple 
industry to improve the interpretation of $V$. inaequalis infection risk and hence to facilitate better decision-making on fungicide selection and timing.

\section{Concept}

\section{INTEGRATED RISK MODEL DESCRIPTION}

The integrated risk model outputs an infection risk index that is the product of three component risk indexes: (1) ascospore availability (maturation and release), (2) wetnessbased infection risk and (3) susceptible leaf area. The onset of an infection period is initiated by ascospore release, which requires rainfall (MacHardy 1996). Assessment of disease risk occurs daily, although hourly weather data are required to specify the time of rainfall, surface wetness and temperature.

\section{Ascospore maturation and release}

The maturation of ascospores in fallen leaves on the ground, between September and December, is simulated using accumulated temperature (Beresford 1999). Newly matured ascospores, together with those unreleased from previous days, are released by the next rainfall event during daylight hours. Negligible ascospore release is considered to occur at night (MacHardy 1996).

The integrated model differs from the previous ascospore model (Beresford 1999) in that a transition is used around dawn and dusk to give a gradual change in the potential for ascospore release between day and night. At other times during daylight hours the integrated model releases a proportion less than 1.0 of the ascospores available. This provides flexibility to incorporate new information into the model on factors affecting the release of ascospores. The integrated model releases ascospores each rainy day and assumes that a defined total number of spores is available during the season. In contrast, the previous ascospore model represented release as a percentage of the season's crop. Using a definite number gives future potential to incorporate an indicator for amount of inoculum in the orchard, e.g. potential ascospore dose (Gadoury \& MacHardy 1986).

\section{Wetness-based infection risk}

Conditions suitable for the infection of leaf and fruit tissues by ascospores are identified using the surface wetness duration and temperature criteria of Mills \& Laplante (1954), with the modification of MacHardy \& Gadoury (1989). The algorithm outputs a continuous variable based on the five wetness-based risk categories previously used: nil, marginal, light, moderate and severe (Beresford \& Spink 1992). Infection risk is only output if the surface wetness criteria have been fulfilled for five or more hours.

\section{Susceptible leaf area}

The susceptible area model simulates the amount of expanding (susceptible) leaf area on a tree in relation to temperature. This model was derived from unpublished data obtained from Royal Gala on M.26 rootstock in Nelson. The expanding leaf area followed the general pattern described by Manktelow (1998). In the model, expanding leaf area is simulated on four shoot types: (1) high-vigour extension, (2) medium-vigour extension (including lateral extension shoots and bourse shoots), (3) flowering spur and (4) nonflowering spur or short bourse shoots. Total expanding leaf area per tree is summed from the product of expanding leaf area of each shoot type and the number of each shoot type on a tree.

\section{Model testing}

To evaluate the integrated model's output, it was run on 2003 weather data from electronic weather stations at Havelock North in Hawke's Bay and Riwaka in Nelson. The weather stations were configured as described by Beresford \& Spink (1992). Air temperature was recorded in a Stevenson screen, surface wetness was recorded using a flat plate wetness sensor and rainfall was recorded with a tipping bucket raingauge with $0.1 \mathrm{~mm}$ sensitivity. All instruments were operated at $1.5 \mathrm{~m}$ height outside of apple canopies. 


\section{RESULTS}

The incidence of integrated infection risk during spring 2003 for both Hawke's Bay and Nelson was determined mostly by wetness-based infection risk (Figs 1a \& 1b). However, the magnitude of the risk varied according to both the numbers of ascospores released, as influenced by daily maturation, and time since last rainfall, as well as by the susceptible leaf area (Figs $2 \mathrm{a} \& 2 \mathrm{~b}$ ). The time at which greatest infection risk occurred in Hawke's Bay was on 24 October and resulted from release of a large number of ascospores after a long dry spell (Fig. 1a). In Nelson the greatest risk occurred on 11 October and was associated with a very long wet period (Fig. 1b).
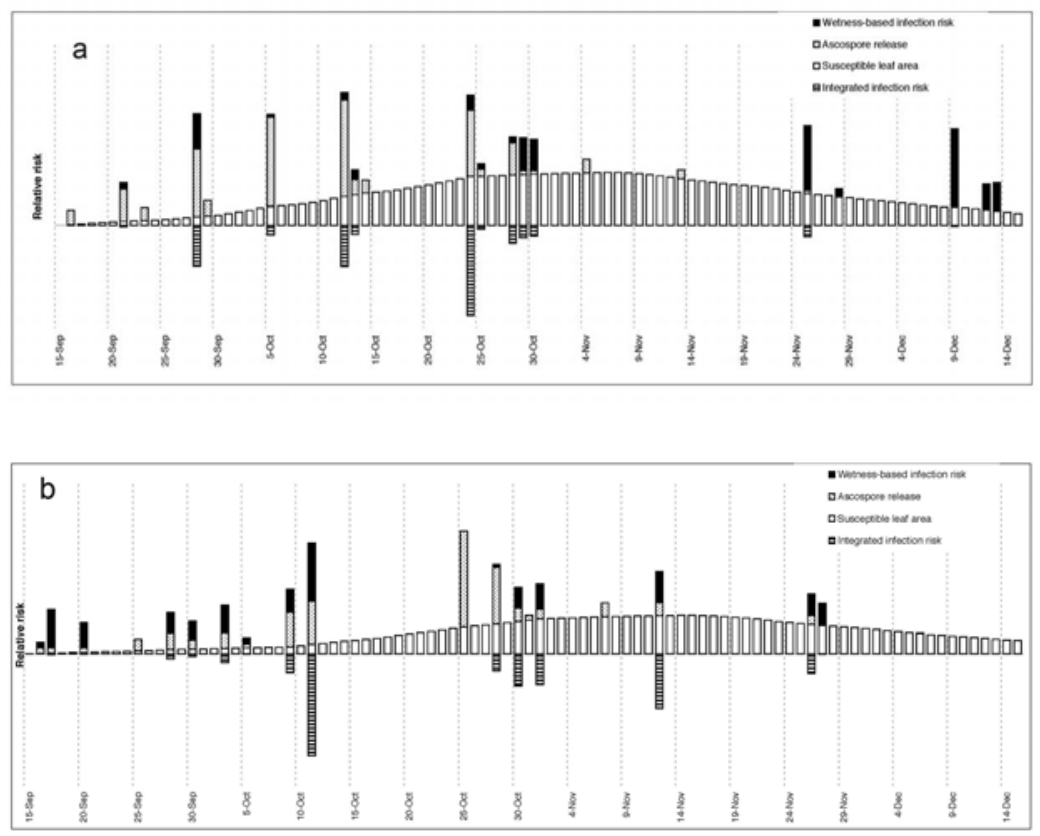

FIGURE 1: Daily output from the integrated risk model (inverted bars) and its three risk components for (a) Hawke's Bay and (b) Nelson in 2003.

The ascospore maturation rate varied from day to day with variations in temperature. In Hawke's Bay it peaked between 25 September and 15 October (Fig. 2a), and in Nelson a little later due to cooler temperatures, between 5 and 25 October (Fig. 2b). Relative amount of susceptible leaf area rose to a peak in Hawke's Bay between 25 and 30 October (Fig. 2a) and in Nelson it was again later, between 4 and 9 November (Fig. 2b).

There were occasions when the ascospore release predicted by daytime rainfall did occur, but wetness did not continue long enough for an infection risk to be predicted. For example, in Nelson on 25 October (Fig. 1b) there was substantial ascospore release predicted after a period with no rainfall, during which the model accumulated unreleased ascospores. There was no wetness-based infection risk associated with this ascospore release. Inspection of the associated weather data showed that this predicted release was caused by $0.2 \mathrm{~mm}$ rainfall at $7 \mathrm{pm}$, followed by only three hours of wetness. A similar occurrence happened in Hawke's Bay on 5 October (Fig. 1a), although this time a small degree of wetness-based infection risk was predicted. Inspection of the weather data 
showed that this wet period did not meet the "Marginal" category of the old risk model (Beresford \& Spink 1992), and would therefore not have been reported by that model as an infection period.
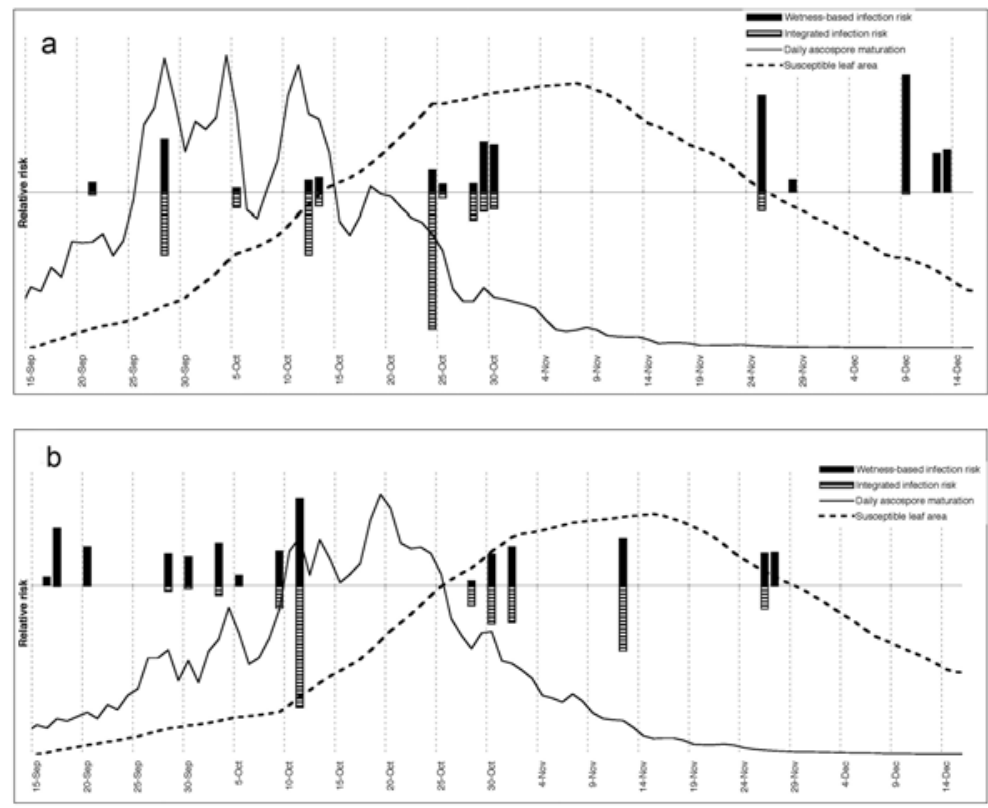

FIGURE 2: Seasonal trends in predicted rate of ascopsore maturation and susceptible leaf area, together with daily values of predicted wetnessbased infection risk and integrated risk (inverted bars) for (a) Hawke's Bay and (b) Nelson in 2003.

\section{DISCUSSION}

This new integrated model gives a different interpretation of the relative infection risk in different parts of the season, compared to that given by wetness-based "Mills" risk alone. This was due to the additional risk weightings given by the model's ascospore release and susceptible leaf area components. These weightings comprise partly the gradual trends in ascospore maturation rate and susceptible leaf area that occur in response to seasonal temperatures, and partly the discontinuous pattern of ascospore release, as determined by rainfall events. The inclusion of susceptible leaf area in the integrated model predicted a hitherto unidentified increase in overall infection risk during the period immediately after peak ascospore maturation.

The new model, in effect, reports wetness-based infection risk below the old "marginal" category (Beresford \& Spink 1992), as a result of reporting wet periods down to five hours duration. The new model would appear to be more conservative than the old model, possibly leading to over-reporting of potential risk. However, the wetness-based risk output is now proportional, rather than categorical, and it is combined with the other risk components. The integrated output therefore encapsulates much more useful information about overall infection risk than was available in the old "Mills periods" approach. Implementation of 
this model in a software application will require the transparent reporting of all three infection risk components that make up the overall risk.

In practical use, this model will still require users to occasionally inspect weather details associated with identified infection events. For example, the occurrence of a large predicted ascospore release but no wetness-based infection risk could lead to ungerminated ascospores surviving until the next nighttime wet period. Such events would need to be individually interpreted by the user, although it should be possible in the future to build such interpretation into the model.

The integrated risk model now needs to be tested in field trials where fungicides are applied in response to predicted infection risk and compared with other fungicide timing strategies. To complete development of the integrated risk model, further information is needed on the effects of cultivar, rootstock, training system and tree age on patterns of susceptible leaf area production. In addition, changes in the susceptibility of fruit to infection need to be incorporated into the model.

Once implemented in a software application, this model should allow apple growers to more effectively assess the main factors that determine infection risk by $V$. inaequalis and thereby help them to make more rational decisions of the selection and timing of fungicides for scab management. The implementation process will need to include appropriate training for apple industry personnel on the use and interpretation of the model.

\section{ACKNOWLEDGEMENTS}

Pipfruit New Zealand Inc. and The Foundation for Research, Science and Technology are gratefully acknowledged for funding this research.

\section{REFERENCES}

Beresford, R.M. 1999: Validation of an ascospore release prediction model for apple black spot (Venturia inaequalis). Proc. 52nd N.Z. Plant Protection Conf: 148-152.

Beresford, R.M.; Spink, M. 1992: A national disease forecasting system for apple black spot (Venturia inaequalis) in New Zealand. Acta Hort. 313: 285-296.

Gadoury, D.M.; MacHardy, W.E. 1986: Forecasting ascospore dose of Venturia inaequalis in commercial apple orchards. Phytopath. 76: 112-118.

MacHardy, W.E. 1996: Apple scab biology, epidemiology and management. APS Press, American Phytopathological Society, St Paul, Minnesota, USA. Pp. 280-292.

MacHardy, W.E.; Gadoury, D.M. 1989: A revision of Mills' criteria for predicting apple scab infection periods. Phytopath. 79: 304-310.

Manktelow, D.W.L. 1998: Factors affecting spray deposits and their biological affects on New Zealand apple canopies. PhD thesis, Massey University, Palmerston North, New Zealand. 192 p.

Mills, W.D.; Laplante, A.A. 1954: Apple scab. In: Diseases and insects in the orchard. Cornell Extension Bulletin 711: 20-28.

Schwabe, W.F.S. 1979: Changes in scab susceptibility of apple leaves as influenced by age. Phytophylactica 11: 53-56. 